\title{
The Effect of Methotrimeprazine on Arterial Blood Gases in Human Volunteers
}

\author{
Elemer K. Zsigmond, MD, and Kathleen Flynn, BS
}

\begin{abstract}
Since methotrimeprazine proved to be both an effective tranquilizer and analgesic, its effect in a tranquilizing dose of $0.15 \mathrm{mg} / \mathrm{kg}$ on the arterial blood gases was determined in human volunteers. Because of the known potentiating effect of some phenothiazines on the narcotic-analgesic induced respiratory depression and analgesia, the effect of methotrimeprazine on the meperidine-induced respiratory depression was also studied. Before, and at five minute intervals after the administration of the test drugs, $\mathrm{PaO}_{2}, \mathrm{PaCO}_{2}$ and $\mathrm{pH}$ were determined by a Radiometer Copenhagen Blood Gas Analyzer (Radiometer Copenhagen, 72 Endruvej, Denmark) through a Riley-needle. Continuous ECG lead II tracings were taken during the experiment. No significant decrease in $\mathrm{PaO}_{2}$ or increase in $\mathrm{PaCO}_{2}(\mathrm{P}<0.01)$ was observed in 6 healthy volunteers (mean age $=25$ yrs) after 0.15 $\mathrm{mg} / \mathrm{kg}$ i.v. methotrimeprazine. In 19 volunteers (mean age $=32 \mathrm{yrs}$ ), the intravenous infusion of $1.5 \mathrm{mg} / \mathrm{kg}$ meperidine caused significant decrease in $\mathrm{PaO}_{2}$ and increase in $\mathrm{PaCO}_{2}$ five minutes after its administration. The combined administration of both drugs to 6 volunteers (mean age $=23 \mathrm{yr}$ ) caused initially the same decrease in $\mathrm{PaO}_{2}$ as after meperidine alone with subsequent increase in $\mathrm{PaO}_{2}$ over normal levels, however, the $\mathrm{PaCO}_{2}$ significantly increased both as compared to baseline values and as compared with meperidine alone. The $\mathrm{pH}$ reductions after the combination of both drugs were greater than after meperidine alone, which in combination with the $\mathrm{PaCO}_{2}$ values confirms the potentiation of meperidine-induced respiratory depression by methotrimeprazine. The results indicate the methotrimeprazine alone causes no significant respiratory depression, but it potentiates the respiratory depression caused by meperidine.
\end{abstract}

$\mathbf{T}$ ranquilizers are commonly used to reduce anxiety and restlessness in psychiatric, critically ill, cardiac, and surgical patients and for the so-called ataract analgesia, a new anesthetic technique based on the combined use of tranquilizers and narcotic analgesics. Although the use of methotrimeprazine declined to a great extent in the past two decades since our original study was conducted, there is a revival of interest in its use not only for analgesia during surgical anesthesia but also in its use in the management of cancer pain. ${ }^{1-5}$ Therefore, it is essential to know if and to what extent a particular tranquilizer depresses respiration.

Methotrimeprazine is both an effective tranquilizer $^{6}$ and a potent analgesic agent ${ }^{7}$ and has a unique

From the Department of Anesthesiology and Research Laboratory, University of Michigan Medical Center, Ann Arbor, Michigan. This work was presented at the American Therapeutic Society Meeting, June 21, 1970, Chicago, Illinois. Address for reprints: E. K. Zsigmond, M.D., Department of Anesthesiology, University of Illinois Medical Center, 1740 W. Taylor Street, Chicago, IL 60612 place in our armamentarium of drugs. Ample evidence has been presented for its tranquilizing, antihistaminic, anti-serotonin and antiemetic effect in the literature.$^{6-10}$ Double-blind studies on its analgesic effect for the relief of postoperative pain by Keats and associates ${ }^{11}$ and Lasagna and DeKornfeld ${ }^{12}$ revealed that $10 \mathrm{mg} / 70 \mathrm{~kg}$ of methotrimeprazine equals the effect of $10 \mathrm{mg} / 70 \mathrm{~kg}$ morphine. A double-blind study on the efficacy of $0.2,0.15$ and 0.10 $\mathrm{mg} / \mathrm{kg}$ i.v. methotrimeprazine conducted prior to its evaluation of the respiratory effects* demonstrated that $0.1 \mathrm{mg} / \mathrm{kg}$ adequately relieved preoperative anxiety without adverse circulatory and respiratory effects in 120 surgical patients. The lack of respiratory depressant effect of methotrimeprazine was shown earlier by the studies of Pearson and DeKornfeld, ${ }^{13}$ who could not find a significant shift in the $\mathrm{CO}_{2}$ ventilation response curves in six volunteers receiving $0.2 \mathrm{mg} / \mathrm{kg}$ methotrimeprazine intravenously.

* Unpublished data. 
TABLE I

The Effect of Premedications on the $\mathrm{PaO}_{2}$ in Healthy Human Volunteers

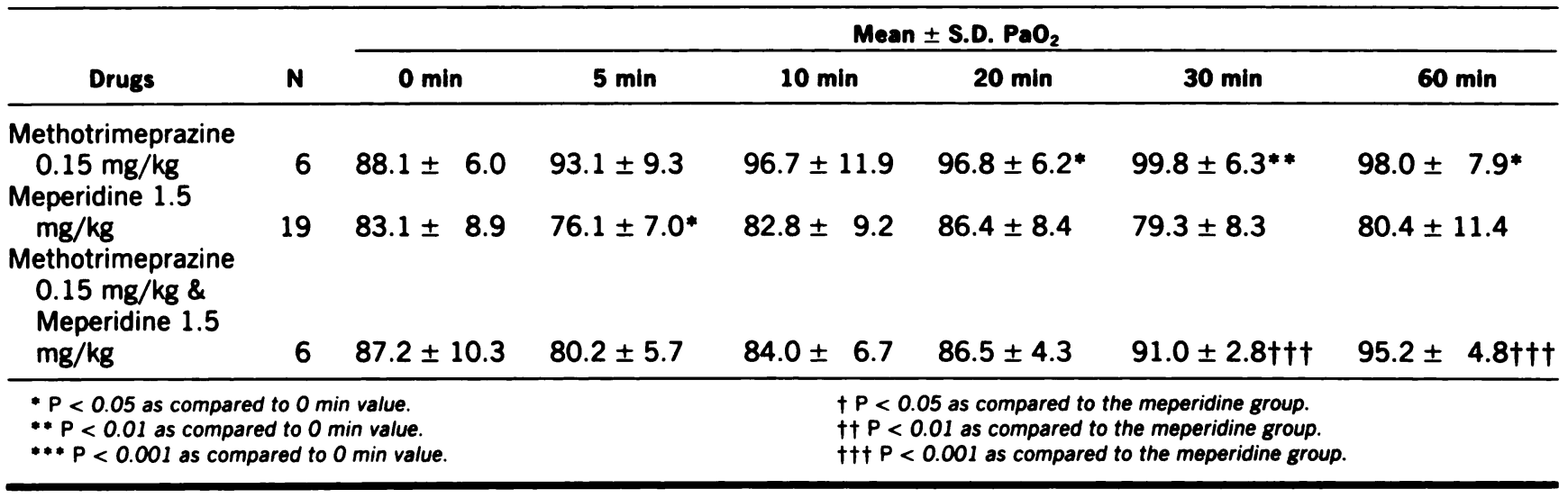

Based on these findings, we believed that methotrimeprazine may be a potential single agent for the induction and maintenance of neuroleptanalgesia, thereby replacing the mixture of tranquilizers and analgesics. Before the initiation of a clinical trial for neuroleptanalgesia, further studies on its respiratory and circulatory effect in human volunteers were indicated. Since it may be also used in combination with other analgesic agents before, during or after anesthesia, studies were planned on its effect on the narcotic-caused respiratory depression. This report encompasses the results of blood gas studies in healthy volunteers after methotrimeprazine, meperidine and their combinations.

\section{METHODS}

Thirty one healthy adult volunteers of both sexes were studied. The criteria for the selection were: 1) individuals with no systemic disease, 2) no pregnant women, 3) no minors, 4) no individuals habituated to or on drugs.

Six volunteers with a mean age of 25 years (21-26) received $0.15 \mathrm{mg} / \mathrm{kg}$ methotrimeprazine; nineteen volunteers with a mean age of 32 years (19-52) were administered $1.5 \mathrm{mg} / \mathrm{kg}$ of meperidine; six volunteers with a mean age of 23 years $(20-26)$ were given a combination of $0.15 \mathrm{mg} / \mathrm{kg}$ methotrimeprazine with $1.5 \mathrm{mg} / \mathrm{kg}$ meperidine.

After admission to the Anesthesia Research Unit, a 20 ga. Riley needle was inserted into the brachial artery contralateral to the predominant arm. After a 20 minute rest period, two baseline blood gas samples were taken. If the two baseline values were within $5 \%$, the study was begun. All the studies were carried out in the supine position.

The $\mathrm{PaO}_{2}, \mathrm{PaCO}_{2}, \mathrm{pH}$ and base excess were determined on a Radiometer Copenhagen Blood Gas Analyzer according to the equilibration technique of Astrup at 5, 10, 20, 30 and 60 minutes following the intravenous administration of the test medications. The test medications were always administered intravenously in $50 \mathrm{ml}$ physiologic saline solution infused by a Harvard-pump over a 2 minute period. Lead II ECG and direct arterial blood pressure via the brachial artery were continuously monitored throughout the study.

\section{RESULTS}

\section{Methotrimeprazine}

Methotrimeprazine caused no significant decrease $(P<0.05)$ in $\mathrm{PaO}_{2}$ at any time after its administration, but rather a statistically significant increase after 20 min. in $\mathrm{PaO}_{2}$, which peaked at 30 minutes (Table I, Fig. 1). No significant $(P<0.05)$ elevation in $\mathrm{PaCO}_{2}$ was observed at any time after methotrimeprazine (Table II, Fig. 1). pH and base excess also remained unchanged (Table III). These findings indicate that methotrimeprazine causes no significant detectable respiratory depression by blood gas determinations.

Meperidine alone caused a significant reduction in $\mathrm{PaO}_{2}$ (Table I), and a significant increase $(P<0.05)$ in $\mathrm{PaCO}_{2}$ only at $5 \mathrm{~min}$. (Table II) but no reduction in pH and base excess (Table III). 
The combination of methotrimeprazine with meperidine resulted initially in no greater reduction in $\mathrm{PaO}_{2}$ than meperidine alone at 5 minutes (Table I, Fig. 1). At 30 minutes and 60 minutes, even significant increases in $\mathrm{PaO}_{2}(P<0.001)$ were observed in the group of patients receiving methotrimeprazine in combination with meperidine as compared to those receiving meperidine alone (Table I). These changes, however, were not significant when compared with baseline. The combination of methotrimeprazine with meperidine caused significant increases in $\mathrm{PaCO}_{2}$ at all times as compared to the baseline (Table II). Furthermore, significantly higher $\mathrm{PaCO}_{2}$ values (at $P<0.001$ and 0.05 ) were found in the group of volunteers receiving the combination as compared to those receiving meperidine alone at 20 and 30 minutes (Table II). Since the $\mathrm{pH}$ reductions were identical to the $\mathrm{PaCO}_{2}$ increases following the drug combination, methotrimeprazine markedly increased the respiratory depression caused by meperidine alone (Table III, Fig. 1).

\section{DISCUSSION}

This is the first report on the effect of methotrimeprazine on arterial blood gases in healthy volunteers and on its possible potentiating effect on the meperidine induced respiratory depression. Our findings corroborate some earlier reports on the potentiation of the narcotic-induced respiratory depression by phenothiazines, especially after their intravenous injection in rapid sequence. ${ }^{14.15}$ The excessive sedation, after the combination of meperidine and methotrimeprazine, which resulted in most instances in deep sleep, might have also contributed to the ele-

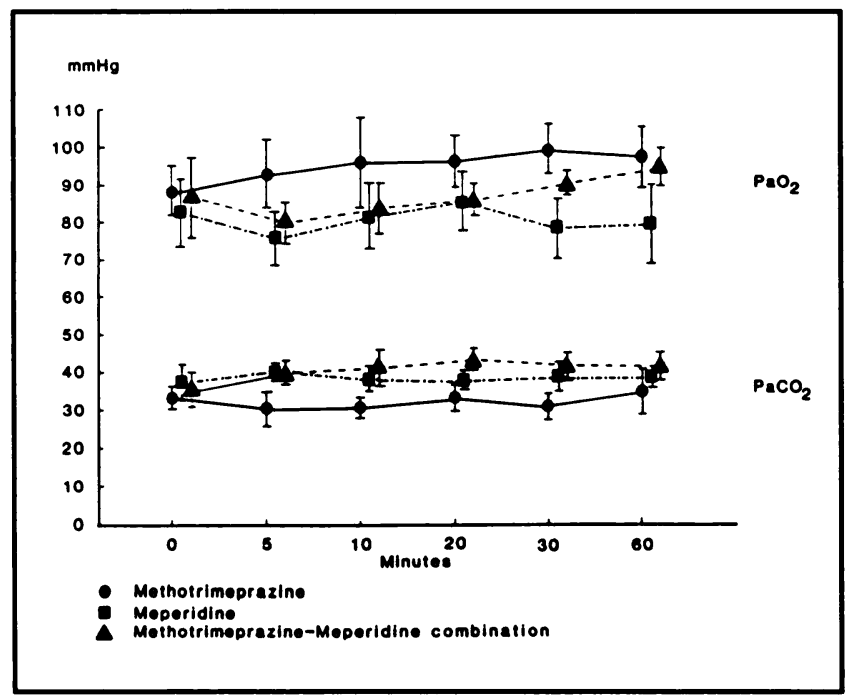

Figure. Arterial blood gas changes following intravenous administration of $0.15 \mathrm{mg} / \mathrm{kg}$ methotrimeprazine, $1.5 \mathrm{mg} / \mathrm{kg}$ meperidine and their combination. Upper lines represent $\mathrm{PaO}_{2}$ and lower lines represent $\mathrm{PaCO}_{2}$. The individual symbols represent means \pm standard deviation from the mean ( \pm S.D.). For statistical significance, we refer the reader to Tables I-III, since the results with the drug combination was compared not only to the baseline but also to the meperidine group. Crowding of the presentation of statistical significance was thereby avoided on the Figure.

vation of arterial carbon dioxide tension. However, the increase in $\mathrm{PaCO}_{2}$ cannot be completely explained by the sleep alone, since its magnitude exceeded that reported in natural sleep. ${ }^{16.17}$

However, the significant differences between the $\mathrm{pH}$ changes that followed the administration of meperidine in combination with methotrimeprazine ei-

\section{TABLE II}

\begin{tabular}{|c|c|c|c|c|c|c|c|}
\hline \multicolumn{8}{|c|}{ The Effect of Premedications on the $\mathrm{PaCO}_{2}$ in Healthy Human Volunteers } \\
\hline \multirow[b]{2}{*}{ Drugs } & \multirow[b]{2}{*}{$\mathbf{N}$} & \multicolumn{6}{|c|}{ Mean \pm S.D. $\mathrm{PaCO}_{2}$} \\
\hline & & $0 \mathrm{~min}$ & $5 \mathrm{~min}$ & $10 \mathrm{~min}$ & $20 \mathrm{~min}$ & $30 \mathrm{~min}$ & $60 \mathrm{~min}$ \\
\hline \multirow{3}{*}{$\begin{array}{l}\text { Methotrimeprazine } \\
0.15 \mathrm{mg} / \mathrm{kg} \\
\text { Meperidine } 1.5 \\
\mathrm{mg} / \mathrm{kg} \\
\text { Methotrimeprazine } \\
0.15 \mathrm{mg} / \mathrm{kg} \& \\
\text { Meperidine } 1.5 \\
\mathrm{mg} / \mathrm{kg}\end{array}$} & 6 & $33.5 \pm 2.3$ & $30.9 \pm 4.8$ & $31.1 \pm 2.0$ & $33.6 \pm 3.1$ & $31.7 \pm 2.7$ & $35.2 \pm 5.4$ \\
\hline & 19 & $37.7 \pm 3.8$ & $40.3 \pm 1.8^{* *}$ & $38.6 \pm 2.9$ & $38.2 \pm 1.5$ & $39.2 \pm 3.5$ & $39.3 \pm 2.9$ \\
\hline & 6 & $35.8 \pm 3.5$ & $40.0 \pm 1.7^{*}$ & $41.7 \pm 4.2^{*}$ & $43.7 \pm 1.7 * * * \dagger+\dagger$ & $42.3 \pm 2.8^{* *} \dagger$ & $41.8 \pm 2.7^{* *}$ \\
\hline \multicolumn{4}{|c|}{$\begin{array}{l}\because P<0.05 \text { as compared to } 0 \text { min value. } \\
\because \because P<0.01 \text { as compared to } 0 \text { min value. } \\
\because * P<0.001 \text { as compared to } 0 \text { min value. }\end{array}$} & \multicolumn{3}{|c|}{$\begin{array}{l}t P<0.05 \text { as compared to the meperidine group. } \\
t+P<0.01 \text { as compared to the meperidine group. } \\
+t+P<0.001 \text { as compared to the meperidine group. }\end{array}$} & \\
\hline
\end{tabular}


TABLE III

\begin{tabular}{|c|c|c|c|c|c|c|c|}
\hline \multirow[b]{3}{*}{ Druges } & \multirow[b]{3}{*}{$\mathbf{N}$} & \multicolumn{6}{|c|}{ The Effect of Premedications on the pH Values in Healthy Volunteers } \\
\hline & & \multicolumn{6}{|c|}{ Mean \pm S.D. pH } \\
\hline & & $0 \mathrm{~min}$ & $5 \mathrm{~min}$ & $10 \mathrm{~min}$ & $20 \mathrm{~min}$ & $30 \mathrm{~min}$ & $60 \mathrm{~min}$ \\
\hline \multirow{2}{*}{$\begin{array}{l}\text { Methotrimeprazine } \\
0.15 \mathrm{mg} / \mathrm{kg} \\
\text { Meperidine } 1.5 \\
\mathrm{mg} / \mathrm{kg} \\
\text { Methotrimeprazine } \\
0.15 \mathrm{mg} / \mathrm{kg} \mathrm{\&} \\
\text { Meperidine } 1.5 \\
\mathrm{mg} / \mathrm{kg}\end{array}$} & 6 & $7.42 \pm 0.01$ & $7.42 \pm 0.02$ & $7.42 \pm 0.01$ & $7.42 \pm 0.02$ & $7.42 \pm 0.02$ & $7.40 \pm 0.03$ \\
\hline & 19 & $7.39 \pm 0.02$ & $7.38 \pm 0.03$ & $7.38 \pm 0.03$ & $7.38 \pm 0.02$ & $7.38 \pm 0.02$ & $7.38 \pm 0.03$ \\
\hline \multicolumn{4}{|c|}{$\begin{array}{l}\because P<0.05 \text { as compared to } 0 \text { min value. } \\
\because \because P<0.01 \text { as compared to } 0 \text { min value. } \\
\because \cdots P<0.001 \text { as compared to } 0 \text { min value. }\end{array}$} & \multicolumn{3}{|c|}{$\begin{array}{l}+\mathrm{P}<0.05 \text { as compared to the meperidine group. } \\
+\dagger \mathrm{P}<0.01 \text { as compared to the meperidine group. } \\
+t+\mathrm{P}<0.001 \text { as compared to the meperidine group. }\end{array}$} & \\
\hline
\end{tabular}

ther as compared with the baseline or to those caused by meperidine alone at the $P<0.01$ and $P$ $<0.001$ probability level indicate a marked potentiation of the respiratory depression by methotrimeprazine. We must emphasize that in clinical practice such large intravenous doses of meperidine and methotrimeprazine, especially in combination, ought to be avoided, as this combination may result in profound sleep lasting for several hours accompanied with marked respiratory acidosis.

The findings indicate that $0.15 \mathrm{mg} / \mathrm{kg}$ i.v. methotrimeprazine alone, which is sufficient dose for relief of either pain or anxiety, causes no significant changes in $\mathrm{PaO}_{2}, \mathrm{PaCO}_{2}, \mathrm{pH}$ or base excess in healthy human volunteers. Subsequent studies ${ }^{5.18 .19}$ corroborated our finding on the lack of respiratory depression caused by methotrimeprazine. Petts and Pleuvry ${ }^{18}$ observed a lack of significant displacement of the ventilatory response curve to $\mathrm{CO}_{2}$ to the right following $2.5 \mathrm{mg}$ i.m. methotrimeprazine in 10 healthy volunteers, whereas morphine $5 \mathrm{mg}$ i.m. caused a significant shift to the right in a doubleblind crossover study using the methods of Redpath and Pleuvry. ${ }^{20}$ In their study, however, contrary to our findings, methotrimeprazine caused no further ventilatory depression when combined with morphine in healthy volunteers than morphine alone. This finding may be explained by the suboptimal doses of both drugs used in their study that are not equipotent to the doses used in our study. Moreover, the authors believed that the accuracy and sensitivity of the trial should have been increased by using a greater number of volunteers and by administering the drugs on a $\mathrm{mg} / \mathrm{kg}$ basis rather than in a fixed $\mathrm{mg}$ dose regardless of weight. In contrast, optimal, effective analgesic doses of $1.5 \mathrm{mg} / \mathrm{kg}$ meperidine i.v. caused a significant reduction in $\mathrm{PaO}_{2}$ at 5 and 10 minute in both healthy volunteers and lung disease patients, that may cause severe decrease in oxygen saturation in patients with chronic obstructive lung disease as we previously published in this journal. $^{21.22}$ Therefore, methotrimeprazine has preference to meperidine as an analgesic agent, when used alone in patients in whom respiratory depression should be avoided.

Double-blind studies by Radnay et al. ${ }^{19}$ provided new evidence for the advantages of methotrimeprazine over meperidine in neuroleptanalgesia. They observed in their double-blind study in anesthetized patients, supplemented by either of these drugs as an analgesic component, that respiratory parameters were little affected by methotrimeprazine while ventilation was markedly depressed by meperidine. Although in our study methotrimeprazine in combination with meperidine caused no greater reduction in $\mathrm{PaO}_{2}$ than meperidine alone, the significant elevation in $\mathrm{PaCO}_{2}$ and parallel reduction in $\mathrm{pH}$ observed for 60 minutes after the combination indicates either an additive or potentiating of the effect of methotrimeprazine on respiratory depression caused by meperidine. Thus the combination of methotrimeprazine with meperidine should be used cautiously in clinical practice in view of the evidence obtained from our study.

In conclusion: If respiratory depression is to be avoided, methotrimeprazine is safer than meperidine, especially in patients with already impaired ventilation.

We gratefully acknowledge the generous financial support of Lederle Laboratories, American Cyanamid Co., Pearl River, NY 10965 from 1967-70 that made these investigations possible. We 
are also indebted to all 65 volunteers, hospital employees, medical and paramedical personnel, for volunteering for these studies conducted from July 1967-September 1969 in the Research Units of the Anesthesia Department at Allegheny General Hospital Pittsburgh, PA 15212 and at the University of Michigan Medical Center, Ann Arbor, MI 48104.

We also wish to express our gratitude to Judy Colvin for the tedious task of typing and editing the manuscript.

\section{REFERENCES}

1. Albrecht M, Hohner E, Van Ackern K: A rational approach to pain treatment in geriatric patients. $Z$ Gerontol 1987;20(1):23-30.

2. Linscott MS: Analgesics in the management of acute pain. Clin Ther 1986;9(1):9-21.

3. Fischer MV, Eibach J, Schmidt M: Treatment of pain in tumour patients. Anasth Intensivther Notfallmed 1986;21(2):78-81.

4. Stelzner M: Drug-induced postoperative pain relief. Anaesthesiol Reanim 1986;11(5):285-295.

5. Rennemo F, Larsen $R$, Breivik $H$ : Avoiding psychic adverse effects during induction of neurolept anaesthesia with levomepromazine. A double-blind study of levomepromazine and droperidol. Acta Anaesthesiol Scand 1982;26(2):108-111.

6. Courvoisier S, Ducrot R, Fournel J, Julou L: General pharmacodynamic properties of levomepromazine (7044RP). CR Soc Biol 1957;151:1378-1382.

7. Courvoisier S, Leau O: Experimental analgesic activity of levomepromazine. CR Acad Sci 1959;248:3227-3228. Excerpta Med II 1959;12:1286.

8. DuCailar J, Vernette-Durand M, Herail J, Rioux J: Concerning pyrrolamidol: present status of analgesia in general anesthesia. Anesth Analg 1959;16:141-150.

9. DuCailar J, Decourt A, Rioux J: The use of levomepromazine in anesthesiology. Presse Med 1959;67:1645-1646.

10. DuCailar J, Vernette-Durand M, Rioux J, Herail J: A standard technique of intravenous anesthesia without barbiturates; interest in the ataralgesic combination of pyrrolamidol and levomepromazine. Anesth Analg 1959;16:797-807.

11. Keats AS, Telford J, Papadopoulos CN: Clinical report to medical research section. Lederle Laboratories. Unpublished data.

12. Lasagna L, DeKornfeld TJ: Methomeprazine: a new phenothiazine derivative with analgesic properties. JAMA 1961;178:887.

13. Pearson JW, DeKornfeld T]: Effect of methotrimeprazine on respiration. Anesthesiology 1963;24:38-40.

14. Pierce JA, Garofalvo ML. Preoperative medication and its effect on blood gases. JAMA 1965;194:487.

15. Keats AS, Telford J, Kurosu Y: 'Potentiation' of meperidine by promethazine. Anesthesiology 1961;22(1):34-41.

16. Robin ED, Whaley RD, Crump $\mathrm{CH}$, Travis DM: Alveolar gas tensions, pulmonary ventilation and blood $\mathrm{pH}$ during physiologic sleep in normal subjects. J Clin Invest 1958;37:981.

17. Steen SN: The effects of psychotropic drugs on respiration. In: Widdicombe J, ed. International Encyclopedia of Pharmacology and Therapeutics: Section 104: Respiratory Pharmacology. Pergamon Press, Oxford 1981; 129-163.

18. Petts HV, Pleuvry BJ: Interactions of morphine and methotrimeprazine in mouse and man with respect to analgesia, respiration and sedation. Br J Anaesth 1983;55(5):437-441.

19. Radnay PA, Becsey LS, Shah NK, Foldes FF: Comparison of methotrimeprazine and meperidine as components of balanced anesthesia. Anesth Analg 1975;54(6):749-755.

20. Redpath JBS, Pleuvry BJ: Double-blind comparison of the respiratory and sedative effects of codeine phosphate and $( \pm)$-glaucine phosphate in human volunteers. Br J Clin Pharmacol 1982;14:555.

21. Zsigmond EK, Flynn K, Martinez O: Diazepam and meperidine on arterial blood gases in healthy volunteers. J Clin Pharmacol 1974;14:377.

22. Zsigmond EK, Shively JG, Flynn K. Diazepam and meperidine on arterial blood gases in patients with chronic obstructive pulmonary disease. J Clin Pharmacol 1975;15:464-469. 